\section{(6) OPEN ACCESS}

\title{
Acoustic neuroma: potential risk factors and audiometric surveillance in the aluminium industry
}

\author{
Oyebode Taiwo, ${ }^{1}$ Deron Galusha, ${ }^{1}$ Baylah Tessier-Sherman, ${ }^{1}$ Sharon Kirsche, ${ }^{1}$ \\ Linda Cantley, ${ }^{1}$ Martin D Slade, ${ }^{1}$ Mark R Cullen, ${ }^{2}$ A Michael Donoghue ${ }^{3}$
}

\begin{abstract}
${ }^{1}$ Department of Occupational \& Environmental Medicine, Yale School of Medicine, New Haven, Connecticut, USA ${ }^{2}$ Division of General Medical Disciplines, Stanford School of Medicine, Stanford, California, USA

${ }^{3}$ Alcoa of Australia, Applecross, Western Australia, Australia
\end{abstract}

\section{Correspondence to} Dr Mark R Cullen, Division of General Medical Disciplines, Stanford University School of Medicine, 1265 Welch Road, MSOB X-338, Stanford, CA 94305-5411, USA: mrcullen@stanford.edu

Received 14 January 2014 Revised 2 June 2014 Accepted 18 June 2014 Published Online First 11 July 2014

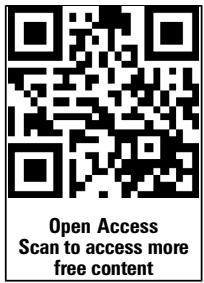

CrossMark

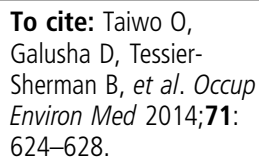

\section{ABSTRACT}

Objectives To look for an association between acoustic neuroma (AN) and participation in a hearing conservation programme (HCP) and also for an association between AN and possible occupational risk factors in the aluminium industry.

Methods We conducted a case-control analysis of a population of US aluminium production workers in 8 smelters and 43 other plants. Using insurance claims data, 97 cases of AN were identified between 1996 and 2009. Each was matched with four controls. Covariates included participation in a HCP, working in an aluminium smelter, working in an electrical job and hearing loss.

Results In the bivariate analyses, covariates associated with AN were participation in the HCP $(\mathrm{OR}=1.72 ; 95 \%$ $\mathrm{Cl} 1.09$ to 2.69$)$ and smelter work $(\mathrm{OR}=1.88 ; 95 \% \mathrm{Cl}$ 1.06 to 3.36). Electrical work was not significant $(\mathrm{OR}=1.60 ; 95 \% \mathrm{Cl} 0.65$ to 3.94). Owing to high participation in the HCP in smelters, multivariate subanalyses were required. In the multivariate analyses, participation in the HCP was the only statistically significant risk factor for AN. In the multivariate analysis restricted to employees not working in a smelter, the $\mathrm{OR}$ was $1.81(95 \% \mathrm{Cl} 1.04$ to 3.17). Hearing loss, an indirect measure of in-ear noise dose, was not predictive of AN.

Conclusions Our results suggest the incidental detection of previously undiagnosed tumours in workers who participated in the company-sponsored HCP. The increased medical surveillance among this population of workers most likely introduced detection bias, leading to the identification of AN cases that would have otherwise remained undetected.

\section{INTRODUCTION}

Three cases of acoustic neuroma (AN) were reported in electrical trade workers at a prebake aluminium smelter in Australia over a 14-year period to 2009. The three workers were all male, 51,49 and 40 years of age, respectively, and had worked at the smelter for 8,14 and 8 years, respectively, at the time of their diagnosis. A preliminary investigation carried out at the plant showed that the three workers were diagnosed with AN through the annual hearing evaluations mandated by the company-instituted hearing conservation programme (HCP). HCPs are designed to prevent noise-induced hearing loss (NIHL) in employees exposed to significant ambient noise levels. One component of traditional HCPs is annual employee audiograms to monitor hearing

\section{What this paper adds}

- We conducted a case-control analysis for acoustic neuroma (AN) in a population of US aluminium production workers using insurance claims data. Each of the 97 cases was matched with four controls.

- In the multivariate analysis, the only statistically significant association with AN was participation in a hearing conservation programme (OR=1.81; $95 \% \mathrm{Cl} 1.04$ to 3.17$)$. 'Smelter work', 'electrical work' and 'electrical work in a smelter' all yielded modestly elevated ORs that did not reach statistical significance.

- Our results suggest that increased medical surveillance among this population of workers in the form of audiometric surveillance introduced detection bias, leading to the identification of AN cases that would otherwise have remained undetected.

- While other exposure covariates were not statistically significantly associated with AN, we cannot exclude the possibility that they are risk factors because of wide Cls.

loss and to evaluate abnormal findings such as unilateral hearing loss without any obvious explanation. Such audiograms require further workup, which typically include imaging studies of the head, to rule out benign growths such as ANs and other types of brain tumours. Australian cancer registries do not systematically record benign ANs and without pertinent health claims data being available for the Australian workforce, an appropriate epidemiological study examining the risk factors for AN was not feasible. Therefore, investigators turned to a much larger US cohort with pertinent health claims data, working in the aluminium industry for the same company that operated the Australian smelter. The same corporate HCP requirements applied in the USA and Australia.

$\mathrm{AN}$ is a slow-growing benign tumour that arises primarily from the vestibular portion of the VIII cranial nerve and lies in the cerebellopontine angle. It causes progressive hearing loss, tinnitus and vertigo. The trigeminal nerve can become involved with diminished corneal sensation. In advanced cases, raised intracranial pressure can occur. Treatment is surgical and less invasive if tumours 
are detected early while they are still small. It is the most frequent intracranial benign tumour, representing $6 \%$ of all intracranial tumours. ${ }^{1}$ There is some evidence to suggest that incidence rates for AN have increased over time. ${ }^{2}$

AN can occur in a sporadic, mostly unilateral form, which accounts for $95 \%$ of cases. Hereditary, mostly bilateral, presentation is associated with type II neurofibromatosis and accounts for the remaining $5 \%$ of AN cases. The aetiology of the sporadic form of AN is largely unknown; however, high-dose ionising radiation is one of the few known risk factors for the disease, an association that has been confirmed in studies of radiation treatments, dental X-rays ${ }^{3}{ }^{4}$ and atomic bomb survivors. $^{5}$

Recently, studies evaluating the relationship between nonionising radiofrequency radiation from mobile phone use and the risk of AN have been conducted, some of which have shown a positive association. ${ }^{6}$ However, other studies of cell phone use and $\mathrm{AN}$ have been negative ${ }^{7}$ or inconclusive because of the relatively short period of observation. ${ }^{9}$

Extremely low-frequency electromagnetic fields (ELF-EMFs) have also been suggested as a risk factor for AN, and are produced as a result of the generation, transmission and use of electric power. ELF-EMFs do not produce ionisation of atomic particles, and consequently they are classified as non-ionising radiation. The electricity required for the electrolytic reduction of aluminium produces static and ELF magnetic fields in the smelter potrooms. ${ }^{10}$ However, a study specifically examining the relationship between occupational exposure to ELF-EMFs and AN did not show an increased risk from EMF exposure. ${ }^{11}$

In addition, a few studies have explored the possible association between $\mathrm{AN}$ and occupational exposure to loud noise. Some of these studies have shown a positive association between occupational noise exposure and the risk of $\mathrm{AN}^{3}{ }^{12}{ }^{13}$ while other studies were unable to demonstrate the same association. ${ }^{12}$ Recently, it has come to light that one of the major issues with measuring health effects of ambient noise exposure is the inability of the investigator to properly adjust for the impact of hearing protection on personal noise attenuation, and subsequently an individual's 'true' at-ear noise exposure. ${ }^{14}$ As a result of this, it is possible that the lack of a consensus in the literature on whether or not noise is a risk factor for AN is based on the fact that prior studies have used ambient noise, and not at-ear noise, as their predictor variable.

Studies examining whether or not different occupations confer additional risk for AN have reported an increased likelihood of AN among teachers, police officers, athletes, gas station attendants, purchasing agents, sales representatives, females working as tailors and truck and conveyor operators. ${ }^{3} 15{ }^{16}$ The risk factors within these occupations are unclear, but some of the studies indicate a possible association with chemical exposures such as mercury, textile dust, benzene ${ }^{16}$ and solvents. ${ }^{3}$ The increased incidence rates in these occupations may also be attributable to a greater likelihood of diagnosis stemming from sociological factors such as education, peer encouragement to seek medical care and better access to care.

Aluminium primary production involves bauxite mining, refining of bauxite to yield alumina and aluminium smelting. The smelting process emits a variety of gases and fumes; including hydrogen fluoride, sulfur dioxide, alumina and fluoride particulates, and coal tar pitch volatiles (CTPVs). CTPVs contain polycyclic aromatic hydrocarbons (PAHs), which are known carcinogens that have been associated with increased risk of lung, bladder and other cancers in predominantly Soderberg aluminium smelter workers. ${ }^{17}$ However, there have been no studies until now that have shown an association between PAH exposure and $\mathrm{AN}$, which is a benign intracranial tumour. Other exposures in aluminium smelters include noise, heat and ELF-EMFs distributed as alternating current from power lines and direct current in aluminium potrooms. The objectives of this study are to look for an association between $\mathrm{AN}$ and participation in a HCP and also for an association between AN and possible occupational risk factors in the aluminium industry.

\section{METHODS}

This study utilised 14 years (1996-2009) of health data from all of Alcoa Inc US aluminium production locations. The locations included 1 alumina refinery, 8 aluminium smelters and 42 other aluminium manufacturing facilities that produce a variety of aluminium products. The data set has been described in other publications. ${ }^{18}$ In brief, Alcoa maintains a number of data sets on its entire US workforce including human resource, health insurance claims (non-work-related), medical surveillance, injury and industrial hygiene records. These data sets have been linked at the individual level, with all personal identifiers removed prior to analyses. The health insurance claims database allowed investigators to review physician diagnoses of $\mathrm{AN}$ for each hospital and outpatient visit made by employees during the study period. The case definition of AN used in this study was at least one insurance claim of AN diagnosis (International Classification of Diseases, ninth revision (ICD-9) 225.1 benign neoplasm of cranial nerves) between 1996 and 2009.

A case-control analysis of the potential risk factors for AN in the workforce was carried out by selecting four controls for each AN case. Controls were selected from employees from all US locations, working at least a day from 1996 to 2009, without an insurance claim for an AN diagnosis. Controls were matched by year of birth, year of hire, employee type (salary vs hourly) and sex and then four controls were randomly selected for each case. The initial exposures of interest, based on established risk factors in the current $\mathrm{AN}$ literature and the initial three Australian cases, were participation in HCP (yes/no), location (smelter/non-smelter), job type (electrical vs non electrical) and hearing loss as an indirect measure of at-ear noise exposure. Electrical jobs included electricians, electrical engineers, electrical technicians and electrical maintenance supervisors.

A previous report had shown that ambient noise is not a reliable measurement of actual in-ear noise dose in aluminium manufacturing workers. ${ }^{14}$ In the absence of personal, at-ear noise measurements, the investigators used hearing loss as a surrogate for at-ear noise exposure, as there is a well-established association between noise exposure and hearing loss. ${ }^{19}$ Thus, audiograms recorded in the ear with the least amount of hearing loss 10 or more years before $\mathrm{AN}$ diagnosis in cases were compared with audiograms of controls, also taken in the same year and from the better ear. The 10 year lag was used to account for latency. Although latency may be longer than 10 years, it is unlikely to be less. The hearing threshold levels were then compared at the individual frequencies $0.5-6 \mathrm{kHz}$, and the averages of $2,3,4 \mathrm{kHz}, 3,4,6 \mathrm{kHz}$, and $0.5,1,2,3 \mathrm{kHz}$ between the cases and controls. The odds of being a case for each $1 \mathrm{~dB}$ increase in hearing threshold level were calculated for all frequencies.

We used logistic regression models to evaluate the association between the potential risk factors and AN cases after matching for date of birth, year of hire, employee type and sex. The variables of interest included HCP (yes/no), location (smelter/nonsmelter), job type (electrical vs non-electrical) and hearing threshold level as a surrogate for at-ear noise exposure. We first 
analysed the unadjusted association between these potential risk factors and AN and then developed a multivariate logistic regression model to analyse the independent associations. Analyses were conducted using SAS V.9.2 (SAS Institute Inc, Cary, North Carolina, USA).

Since participation in the company's HCP among smelter workers is high at $87 \%$, in order to assess the risk associated with smelter exposure we conducted multivariate subanalyses of employees restricted to those participating in the HCP, those not participating in the HCP, those in a smelter location and those not in a smelter location.

Study protocols have been reviewed and approved by the human subjects committees of Stanford University and Yale School of Medicine.

\section{RESULTS}

The cohort from which the cases came and the controls were selected included a total of 118388 workers with 544601 person-years of observation. Twenty per cent of the population worked in a smelter, with a mean age of 44 years and tenure of 19 years. Most workers were hourly, male and Caucasian. Table 1 shows the demographics and other characteristics of the AN cases and controls. There were 97 cases of AN diagnosed in the database between 1996 and 2009 using the case definition of at least one claim of AN. The mean age at diagnosis was 52 years and $73 \%$ of cases were male. The mean duration of work history at the time of diagnosis was 20 years. Nearly $40 \%$ of cases were salaried employees and $58 \%$ participated in the HCP. Only 7\% were employed in electrical jobs. The estimated rate of $\mathrm{AN}$ in this population was 17.8/100 000 person-years, unadjusted for age.

Results for the bivariate analyses are presented in table 2 . Cases of AN were more likely to be included in the HCP $(\mathrm{OR}=1.72 ; 95 \% \mathrm{CI} 1.09$ to 2.69$)$ and more likely to work in a smelter (OR=1.88; 95\% CI 1.06 to 3.36) when compared with controls. Working in an electrical job was also associated with increased risk of AN, although this did not reach statistical significance $(\mathrm{OR}=1.60 ; 95 \% \mathrm{CI} 0.65$ to 3.94$)$. However, since a high proportion of smelter workers are in a HCP $(87 \%)$, the effect of smelter exposure could only be assessed reliably in a subanalysis of people in the HCP. Table 3 presents the results of multivariate analyses of employees restricted to those participating in the HCP, those not participating in the HCP, those in a smelter location and those not in a smelter location. Participation in the HCP was the only statistically significant risk factor for being diagnosed with AN. In the multivariate analysis

Table 1 AN cases and controls: demographics and other characteristics

\begin{tabular}{lcl}
\hline Characteristic & AN case (N=97) & Control (N=388) \\
\hline Age at diagnosis-mean (SD) & $52.0(11.4)$ & Not applicable \\
Tenure at diagnosis-mean (SD) & $20.0(14.2)$ & Not applicable \\
DOB-mean (range) & $1952(1921-1982)$ & $1952(1921-1982)$ \\
Year of hire-mean (range) & $1984(1948-2006)$ & $1984(1948-2006)$ \\
Salaried employees-n (\%) & $38(39.2)$ & $152(39.2)$ \\
Male-n (\%) & $71(73.2)$ & $284(73.2)$ \\
Hearing conservation programme & $56(57.7)$ & $172(44.3)$ \\
participants-n (\%) & & \\
Electrical job-n (\%) & $7(7.2)$ & $18(4.6)$ \\
Smelter workers-n (\%) & $20(20.6)$ & $47(12.1)$ \\
\hline
\end{tabular}

AN, acoustic neuroma; DOB, date of birth.
Table 2 Odds of being an acoustic neuroma case-bivariate analysis

\begin{tabular}{lll}
\hline Characteristic & OR $(95 \% \mathrm{Cl})$ & p Value \\
\hline Hearing conservation programme participation & $1.72(1.09$ to 2.69$)$ & 0.02 \\
Electrical job & $1.60(0.65$ to 3.94$)$ & 0.31 \\
Smelter worker & $1.88(1.06$ to 3.36$)$ & 0.03
\end{tabular}

For each case there were four controls matched on date of birth, year of hire, employee type and sex.

restricted to those employees not working in a smelter location, the OR was 1.81 (95\% CI 1.04 to 3.17).

Table 4 shows the difference in hearing threshold levels between the cases $(n=49)$ and controls $(n=147)$ that were included in a HCP and had an audiogram 10 years prior to the diagnosis of AN. There was no significant difference in the hearing level at the individual frequencies or combined frequencies between the cases and the controls, and thus hearing loss, and most likely at-ear noise exposure, was not predictive of AN in our cohort of aluminium production workers. As such, it was not included in the multivariate analyses.

\section{DISCUSSION}

While the Australian smelter cases initiated interest in undertaking this study and raised the possibility that participation in a HCP may be associated with AN, review of the literature also indicated merit in looking for this association and for other possible occupational risk factors. The Australian cases came to notice anecdotally rather than as the result of a systematic process. In contrast to the US workforce, the Australian workforce does not have a health insurance claims data set, so it was not possible to be sure if all cases in the Australian smelter had been identified, or to undertake an appropriate epidemiological study. In addition to this, AN is a relatively rare tumour, so it was advantageous to study the much larger US population of aluminium production workers.

The results of our study show that the diagnosis of AN in aluminium production workers, based on at least one insurance claim, was statistically significantly associated with participation in a HCP. While the results for 'work in a smelter', 'electrical work' and 'electrical work in a smelter' all showed modestly elevated ORs, they were not statistically significant in the multivariate analyses. Although we have not found these covariates to be risk factors for $\mathrm{AN}$, we cannot exclude the possibility that they are because of the wide CIs due to the limited statistical power. Hearing loss as a surrogate for at-ear noise exposure did not

Table 3 Odds of being an AN case-multivariate analyses

\begin{tabular}{lllll}
\hline Characteristics & OR (95\% Cl) & $\mathbf{p}$ Value & OR $(95 \% \mathrm{Cl})$ & $\mathbf{p}$ Value \\
\hline & Not in HCP & & In HCP \\
Smelter worker & $1.90(0.34$ to 10.52$)$ & 0.464 & $1.59(0.77$ to 3.27$)$ & 0.211 \\
Electrical job & $1.23(0.14$ to 11.18$)$ & 0.855 & $1.29(0.45$ to 3.71$)$ & 0.633 \\
& Not in a smelter location & In a smelter location \\
In HCP & $1.81(1.04$ to 3.17$)$ & 0.036 & $2.02(0.30$ to 13.42$)$ & 0.468 \\
Electrical job & $1.12(0.30$ to 4.17$)$ & 0.862 & $1.54(0.35$ to 6.76$)$ & 0.570
\end{tabular}

For each case there were four controls matched on date of birth, year of hire, employee type and sex. 
Table 4 Hearing threshold levels of cases and controls in HCP* and the odds of being an AN case

\begin{tabular}{|c|c|c|c|c|}
\hline $\begin{array}{l}\text { Hearing in } \\
\text { better ear }\end{array}$ & $\begin{array}{l}\text { AN cases in } \\
\text { HCP }(N=49) \\
\text { Mean (SD) }\end{array}$ & $\begin{array}{l}\text { Controls } \\
\text { in HCP } \\
(\mathrm{N}=147) \\
\text { Mean (SD) }\end{array}$ & OR $(95 \% \mathrm{CI})$ & p Value \\
\hline $0.5 \mathrm{kHz}$ & $6.3(6.2)$ & $7.6(6.3)$ & $0.97(0.91$ to 1.02$)$ & 0.2280 \\
\hline 1 kHz & $8.4(11.7)$ & $7.1(6.5)$ & $1.02(0.98$ to 1.06$)$ & 0.3403 \\
\hline $2 \mathrm{kHz}$ & $10.4(13.3)$ & $9.3(11.2)$ & $1.01(0.98$ to 1.04$)$ & 0.5733 \\
\hline $3 \mathrm{kHz}$ & $20.2(16.9)$ & $19.9(18.7)$ & $1.00(0.98$ to 1.02$)$ & 0.9183 \\
\hline $4 \mathrm{kHz}$ & $25.9(19.8)$ & $26.7(21.8)$ & $1.00(0.98$ to 1.01$)$ & 0.8229 \\
\hline $6 \mathrm{kHz}$ & $26.1(19.7)$ & $29.7(20.1)$ & $0.99(0.97$ to 1.01$)$ & 0.2812 \\
\hline Avg $2,3,4 \mathrm{kHz}$ & $18.8(14.5)$ & $18.6(15.7)$ & $1.00(0.98$ to 1.02$)$ & 0.9354 \\
\hline Avg $3,4,6 \mathrm{kHz}$ & $24.1(17.2)$ & $25.4(18.9)$ & 1.00 (0.98 to 1.01$)$ & 0.6570 \\
\hline $\begin{array}{l}\text { Avg } 0.5 \\
1,2,3 \mathrm{kHz}\end{array}$ & $11.3(10.1)$ & $10.9(8.8)$ & $1.00(0.97$ to 1.04$)$ & 0.8116 \\
\hline \multicolumn{5}{|c|}{$\begin{array}{l}{ }^{*} \text { Hearing threshold levels were compared using audiograms taken } 10 \text { years prior to } \\
\text { the case AN diagnosis. Thus, to be included in this subanalysis, HCP participants had } \\
\text { to have an audiogram record at that time. } \\
\text { For each case there were four controls matched on date of birth, year of hire, } \\
\text { employee type and sex. } \\
\text { AN, acoustic neuroma; Avg, average; HCP, hearing conservation programme }\end{array}$} \\
\hline
\end{tabular}

appear to be a significant factor in the risk of AN in this workforce, and thus was excluded from the final multivariate model.

As previously stated, there is some evidence to suggest that incidence rates for AN have increased over time. ${ }^{2}{ }^{20}$ However, it is not known whether this is a true increase in incidence or that improved and more frequent MRI has increased detection of tumours which previously would have gone undiscovered. ${ }^{21}$ In this study, participation in the company-sponsored HCP was associated with an increased incidence of AN. With increased audiometric surveillance for sensorineural hearing loss, the most common symptom associated with $\mathrm{AN}$, and subsequent medical workup for those with abnormal audiograms, it is not surprising that more ANs were detected in workers involved in the HCP, whereas they would most likely remain undiagnosed in workers who do not have annual audiograms, or in the general population.

Employees are enrolled in the HCP because of occupational exposure to high-noise levels, an exposure that has been hypothesised to cause $\mathrm{AN}^{3}{ }^{3} 12$ Animal experiments have shown that noise can cause mechanical damage to the VIII cranial nerve in rodents. ${ }^{22}$ Consequently, in theory, the damaged nerve cells could cause cell mutation and subsequent proliferation of abnormal cells. However, epidemiological studies looking at the relationship between noise exposure and AN in humans have shown mixed results, and as we discussed, it is possible that the lack of a consensus on whether or not noise is involved in AN pathogenesis is due to the lack of accurate at-ear noise exposure measurements. For that reason, we used hearing loss as a surrogate for noise exposure, which evidence suggests would result in less exposure misclassification, and result in a more valid analysis. This is because at-ear noise exposure is the resultant of ambient noise exposure modified by hearing protection. We know that hearing protection and compliance has been less than ideal over the study period in this workforce and that NIHL has been observed. Hearing loss in the study population is therefore not only the result of age (which is matched for in the analysis) but is also due to noise exposure. When we compared hearing loss in AN cases with controls, we found no evidence for an association between hearing loss and the incidence of AN in this workforce. This suggests that noise exposure may not be a risk factor for AN.
There are several limitations to this study that must be considered. We relied solely on insurance claims data for the diagnosis of $\mathrm{AN}$, using one claim for $\mathrm{AN}$ as the case definition. This may have led to an overestimation of cases if the ICD-9 code for AN was used by physicians suspecting the benign growth and then subsequently ruling it out after further testing. We were unable to further verify the diagnosis of cases.

Another limitation was the absence of exposure data on static and ELF-EMFs in the workplace, which, as previously stated, are exposures that occur in smelter potrooms. ${ }^{10}$ Of the aluminium production plants with workers included in this analysis, only one location had data on ELF-EMF. As a result, we were unable to assess or control for the relationship between EMF and AN in the workforce. However, a study specifically examining the relationship between occupational exposure to ELF-EMFs and AN did not show an increased risk from EMF exposure $^{23}$ and our multivariate analyses showed no statistically significant association between $\mathrm{AN}$ and working in a smelter, although the CIs were wide.

Finally, while we believe that hearing loss is a better proxy for true noise exposure in our study population, it is still not a direct measurement, and relies on the assumption that individuals with greater hearing loss have greater noise exposure. Therefore, our decision to use hearing loss as a proxy for at-ear noise exposure may have resulted in some at-ear noise exposure misclassification. Until better methods for adjusting for hearing protector attenuation or at-ear personal noise measurements become widely available, the relationship between noise exposure and $\mathrm{AN}$ incidence will most likely remain unclear.

Despite the limitations, these results suggest that participation in a HCP will increase the detection of $\mathrm{AN}$, a slow-growing brain tumour, which would otherwise have remained undiagnosed. Affirmative evidence implicating noise, ionising or nonionising radiation or other occupational exposures remains lacking.

Contributors The study was conceived by OT, AMD and MRC. BT-S, SK, LC and MDS conducted the data curation, modelling and analysis. All authors participated in the drafting of the manuscript and making revisions and have approved the final version.

Funding This research was supported by the National Institute on Aging (R01AG026291), by the Alcoa Foundation and by Alcoa.

Competing interests AMD is employed by Alcoa of Australia as Director of Health and Chief Medical Officer. The research process is supervised by an independent Scientific Advisory Board as are all Alcoa-sponsored Environment Health and Safety research activities conducted under the auspices of the Yale-Stanford-Alcoa agreement since 1997.

Ethics approval Yale and Stanford University.

Provenance and peer review Not commissioned; externally peer reviewed.

Data sharing statement As an alternative to providing a deidentified data set to the public domain, the authors allow access for the purpose of reanalyses or appropriate follow-on analyses by any qualified investigator willing to sign a contractual covenant with the host Institution limiting use of data to a specific agreed on purpose and observing the same restrictions as are limited in our contract with Alcoa, such as a 60-day manuscript review for compliance purposes.

Open Access This is an Open Access article distributed in accordance with the Creative Commons Attribution Non Commercial (CC BY-NC 3.0) license, which permits others to distribute, remix, adapt, build upon this work non-commercially, and license their derivative works on different terms, provided the original work is properly cited and the use is non-commercial. See: http://creativecommons.org/ licenses/by-nc/3.0/

\section{REFERENCES}

1 Gal TJ, Shinn J, Huang B. Current epidemiology and management trends in acoustic neuroma. Otolaryngol Head Neck Surg 2010;142:677-81.

2 Tos M, Stangerup S-E, Cayé-Thomasen $P$, et al. What is the real incidence of vestibular schwannoma? Arch Otolaryngol Head Neck Surg 2004;130:216-20. 
3 Preston-Martin S, Thomas DC, Wright WE, et al. Noise trauma in the aetiology of acoustic neuromas in men in Los Angeles County, 1978-1985. Br J Cancer 1989;59:783-6.

4 Ron E, Modan B, Boice JD Jr, et al. Tumors of the brain and nervous system after radiotherapy in childhood. N Engl J Med 1988:319:1033-9.

5 Preston DL, Ron E, Yonehara S, et al. Tumors of the nervous system and pituitary gland associated with atomic bomb radiation exposure. J Natl Cancer Inst 2002;94:1555-63.

6 Khurana VG, Teo C, Kundi M, et al. Cell phones and brain tumors: a review including the long-term epidemiologic data. Surg Neurol $2009 ; 72: 205-14$

7 Christensen HC, Schuz J, Kosteljanetz M, et al. Cellular telephone use and risk of acoustic neuroma. J Epidemiol 2004;159:277-83.

8 Schoemaker MJ, Swerdlow AJ, Ahlbom A, et al. Mobile phone use and risk of acoustic neuroma: results of the interphone case-control study in five North European countries. Br J Cancer 2005;93:842-8.

9 Ahlbom A, Feychting M, Green A, et al. Epidemiologic evidence on mobile phones and tumor risk: a review. Epidemiology 2009;20:639-52.

10 Sim M, Benke G. World at work: hazards and controls in aluminium potrooms. Occup Environ Med 2003;60:989-92.

11 Forssen UM, Lonn S, Ahlbom A, et al. Occupational magnetic field exposure and the risk of acoustic neuroma. Am J Ind Med 2006;49:112-18.

12 Edwards CG, Schwartzbaum JA, Nise G, et al. Occupational noise exposure and risk of acoustic neuroma. Am J Epidemiol 2007;166:1252-8.
13 Hours $\mathrm{M}$, Bernard $\mathrm{M}$, Arslan $\mathrm{M}$, et al. Can loud noise cause acoustic neuroma? Analysis of the INTERPHONE study in France. Occup Environ Med 2009;66:480-6.

14 Rabinowitz PM, Galusha D, Dixon-Ernst C, et al. Do ambient noise exposure levels predict hearing loss in a modern industrial cohort? Occup Environ Med 2007:64:53-9.

15 Prochazka M, Feychting M, Ahlbom A, et al. Occupational exposures and risk of acoustic neuroma. Occup Environ Med 2010;67:66-71.

16 Rajaraman P, De Roos AJ, Stewart PA, et al. Occupation and risk of meningioma and acoustic neuroma in the United States. AM J Ind Med 2004;45:395-407.

17 IARC. IARC monographs on the evaluation of carcinogenic risks to humans. A review of human carcinogens: chemical agents and related occupations. 2012;100F

18 Pollack KM, Agnew J, Slade MD, et al. Use of employer administrative databases to identify systematic causes of injury in aluminum manufacturing. Am J Ind Med 2007;50:676-86.

19 ANSI: Determination of occupational noise exposure and estimation of noise induced hearing impairment. In. Washington, DC; 1966

20 Stangerup S-E, Tos M, Caye-Thomasen $\mathrm{P}$, et al. Increasing annual incidence of vestibular schwannoma and age at diagnosis. J Laryngol Otol 2004;118:622-7.

21 Lin D, Hegarty JL, Fischbein NJ, et al. The prevalence of "incidental" acoustic neuroma. Arch Otolaryngol Head Neck Surg 2005;131:241-4.

22 Hamernik RP, Turrentine G, Roberto M, et al. Anatomical correlates of impulse noise-induced mechanical damage in the cochlea. Hear Res 1984;13:229-47.

23 Forssen UM, Lonn S, Ahlbom A, et al. Occupational magnetic field exposure and the risk of acoustic neuroma. J Ind Med 2006;49:112-18. 